\title{
Ge爻ротато
}

\section{GEOPOTATO demonstrations: Results of 2018/19 season}

H. Hengsdijk, M. Mukul, J. Kazi, J.M. Michielsen, G. Kessel

\section{GEOPOTATO}

External Report 6
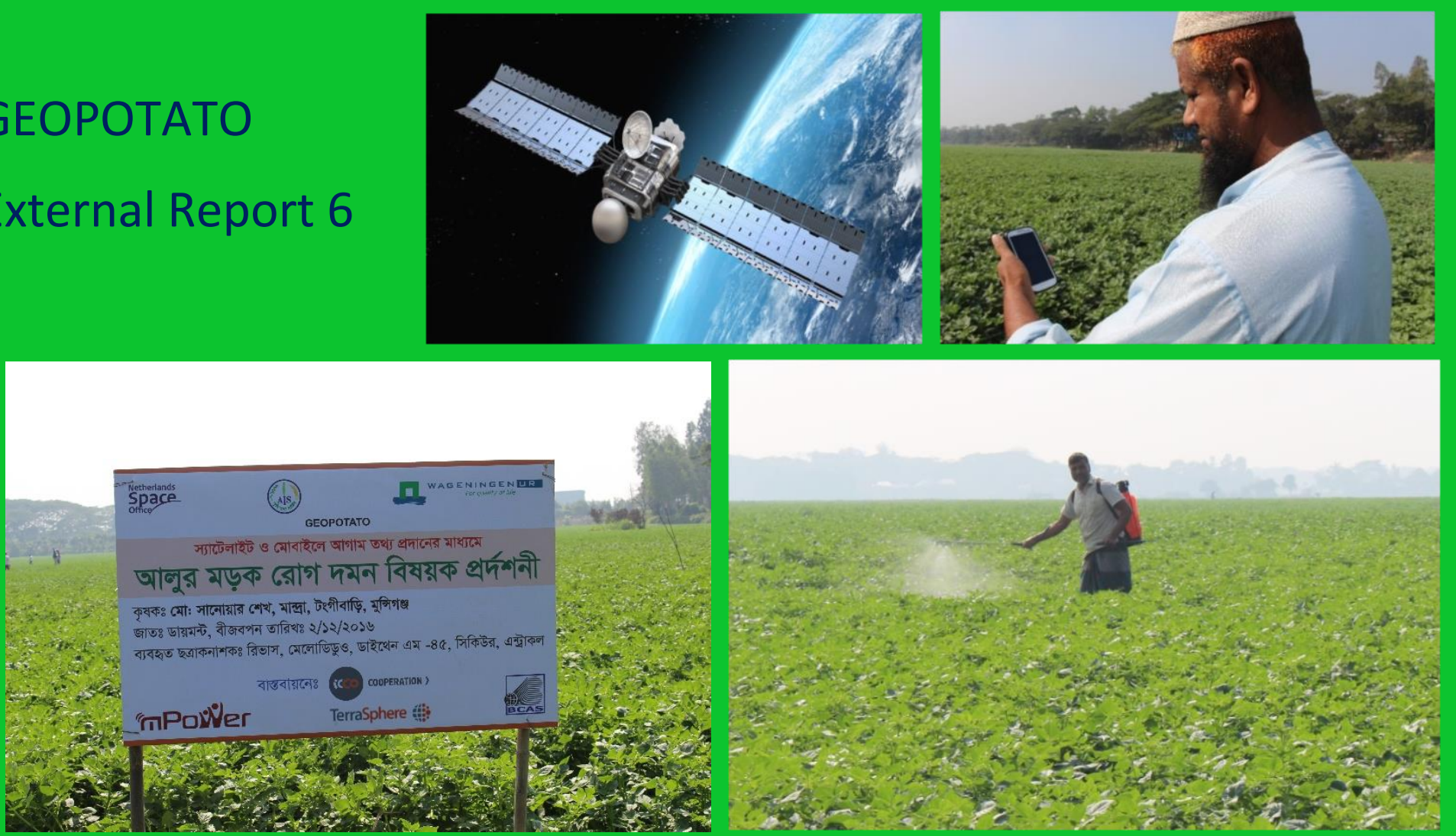


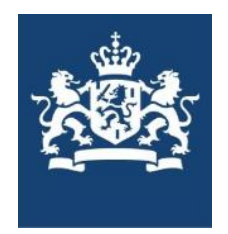

The GEOPOTATO project develops and implements a decision support service (DSS) in Bangladesh to control the late blight disease in potato. Satellite data and various models are important aspects of the DSS. GEOPOTATO aims at becoming the preferred agricultural advice service for potato farmers in Bangladesh. GEOPOTATO is financed by the G4AW program of the Dutch Ministry of Foreign Affairs, which is executed by the Netherlands Space Office (NSO).

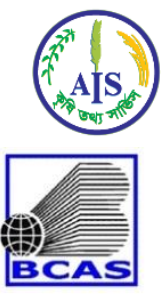

icco

\section{"nPover}

Agricultural Information Services, Ministry of Agriculture, Bangladesh

Bangladesh Centre for Advanced Studies, Bangladesh

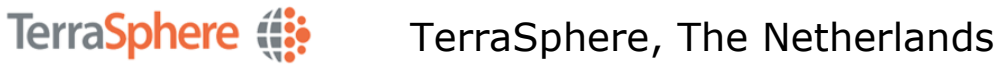

WAGENINGEN

Wageningen University \& Research, The Netherlands

Suggested citation for this report:

Hengsdijk, H., Mukul, M., Kazi, J., Michielsen, J.M., Kessel, G., 2019. GEOPOTATO demonstration plots: Results of 2018/19 season. GEOPOATO Report 6. Dhaka / Wageningen

DOI: https://doi.org/10.18174/517147

\section{(c) (i)(2)}

GEOPOTATO uses a Creative Commons Attribution-Non-Commercial-Share Alike 4.0 International License for its reports

The user may copy, distribute and transmit the work and create derivative works. Third-party material that has been used in the work and to which intellectual property rights apply may not be used without prior permission of the third party concerned. The user must specify the name as stated by the author or licence holder of the work, but not in such a way as to give the impression that the work of the user or the way in which the work has been used are being endorsed. The user may not use this work for commercial purposes. 


\section{GEOPOTATO demonstrations: Results of 2018/19 season}

H. Hengsdijk, M. Mukul, J. Kazi, J.M. Michielsen, G. Kessel

GEOPOTATO External Report 6 


\section{Summary}

The GEOPOTATO project develops a decision-support system (DSS) for farmers in Bangladesh for an improved control of late blight in potato. Late blight, caused by Phytophthora infestans, is a highly infectious and destructive fungal disease in Solanaceous crops, for example, potatoes and tomatoes.

To demonstrate and analyze the performance of the DSS, 19 demonstration fields have been implemented comparing farmers' practice (FP) and the GEOPOTATO practice, i.e. late blight control based on the DSS developed by GEOPOTATO. This report describes the results obtained in the demonstration fields implemented in Munshiganj, Rangpur and Dinajpur during the 2018-2019 potato growing season.

In general, potato growth and production exhibited normal patterns in the demonstration fields. Yields increased with longer growing periods. Late blight pressure was low in the 2018-2019 season according stakeholders. Despite the low late blight pressure average yields obtained in the GEOPOTATO plots was $9 \%$ higher than in the FP plots: $40.8 \mathrm{t} /$ ha vs. $36.9 \mathrm{t} / \mathrm{ha}$. In Dinajpur, yields of GEOPOTATO plots were 19\% higher than FP plots, and in Rangpur and Munshiganj 13\% and 2\% higher, respectively.

Farmers in charge of the FP plots sprayed less than the farmers controlling late blight in the GEOPOTATO plots. Especially in Munshiganj, GEOPOTATO demo farmers sprayed more frequently than FP farmers.

The cost-benefit analysis of the GEOPOTATO control strategy versus the FP strategy showed that higher gross returns, associated with the higher potato yields in Rangpur and Dinajpur, outweighed the higher costs of the fungicides used in the GEOPOTATO strategy. In Munshiganj, the $2 \%$ yield increase in the GEOPOTATO plots was not enough to compensate the higher costs of fungicides. On average, the GEOPOTATO service resulted in an average financial benefit of 173 Euro/ha. 


\section{Table of Contents}

Summary .......................................................................... 4

1. Introduction .......................................................6

2. Material and methods ............................................7

3.1 General set-up and implementation of demonstration fields ............................................. 7

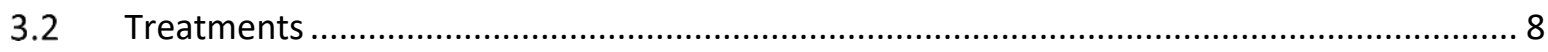

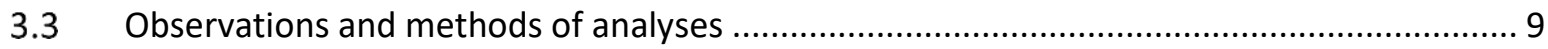

3. Results............................................................. 11

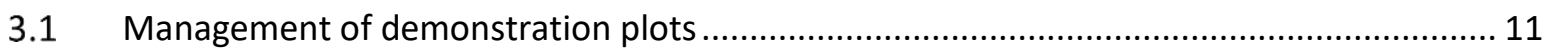

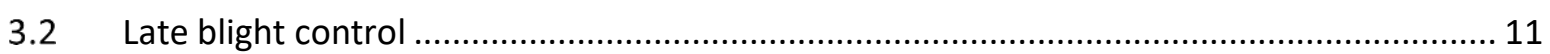

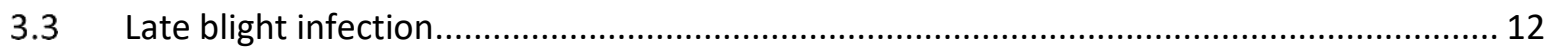

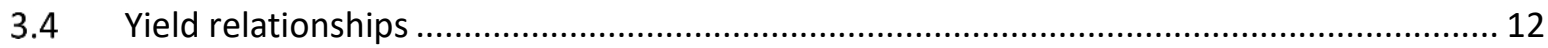

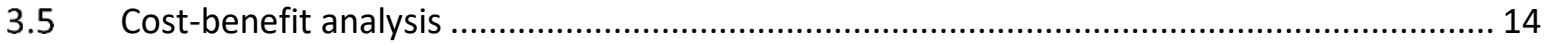

4. Discussions and conclusions .................................... 16

5. References.......................................................... 17

ANNEX I Spray schedule................................................ 18 


\section{Introduction}

The GEOPOTATO project is part of the Geodata for Agriculture and Water (G4AW) facility, which aims to improve food security in developing countries by using satellite data. The Netherlands Space Office (NSO) is executing this program, commissioned by the Dutch Ministry of Foreign Affairs.

GEOPOTATO develops a decision-support service for farmers in Bangladesh for an improved control of late blight in potato. Late blight (Phytophthora infestans) is a highly infectious and destructive fungal disease in Solanaceous crops, for example, potatoes and tomatoes. Especially under favorable weather conditions, i.e. temperatures between 10 and $20^{\circ} \mathrm{C}$ and a relative atmospheric humidity $>85 \%$, the disease spreads very quickly through wind and water and has devastating effects on the crop and yield (Hossain et al. 2008a). The GEOPOTATO decision-support system (DSS) uses a combination of satellite information, weather information and epidemiological- and crop growth models, to forecast infection events of late blight. Timely spray advice through mobile phone for the application of an appropriate fungicide helps farmers to prevent infection of the potato crop. Each time the DSS predicts a risky infection period, subscribed farmers receive an SMS and Voice mail alert recommending farmers to protect their potato crops through a fungicide application.

The aim of the GEOPOTATO project is to reach 100,000 potato farmers with the service after three years. GEOPOTATO pilots the service in three major potato production areas in Bangladesh: in Munshiganj district (central Bangladesh), and in Rangpur and Dinajpur district (both North Bangladesh). Baseline studies were carried out in Munshiganj and Rangpur to better understand the needs, practices and performance of farmers including the context of potato farming in these regions (Pronk et al. 2017a, b).

To show and analyze the performance of the DSS, demonstration fields have been implemented in the service areas comparing 'farmers' practice' and 'GEOPOTATO practice'. In addition, the demonstration fields serve the goal of 'seeing is believing', i.e. to show local farmers the effectiveness of the GEOPOTATO service. In the first operational season of the service (2016-2017), demonstration fields were implemented in Munshiganj (Pronk et al., 2017b). In the second operational season of the DSS (2017-2018) demonstration fields were also implemented in Rangpur (Pronk et al., 2019).

This report describes the results of the demonstration fields that were implemented in Munshiganj, Rangpur and Dinajpur during the third season (2018-2019). Chapter 2 describes the set-up and implementation of the demonstration fields in the 2018-2019 season, which differed from the two earlier seasons. Chapter 3 describes the results of the demonstration fields and Chapter 4 discusses the results and summarizes the conclusions based on the results of the demonstration fields. 


\section{Material and methods}

\subsection{General set-up and implementation of demonstration fields}

In total 19 demonstrations fields were implemented in as many sub-districts (upazilas), six in Munshiganj, seven in Rangpur and six in Dinajpur. Each demonstration consisted of two treatments: a control plot (farmers practice; FP) and a GEOPOTATO plot. In the GEOPOTATO plot, late blight was controlled using the DSS including a sequence of preferred fungicides based on availability and good agricultural practices.

In earlier seasons, the farmer practice and GEOPOTATO plots were managed by the same farmer. This proved to be challenging (Pronk et al., 2017b; 2019): In this situation, plots often need to be sprayed at different moments and, understandably, farmers prefer to apply fungicides to both plots at the same moment, for example, to save time or to save surplus spray liquid of one treatment. In the 2019 - 2019 season, the FP plot and GEOPOTATO plot were managed by different farmers. Farmers with nearby plots were jointly selected by staff of the Department of Agricultural Extension, Sub-Assistant Agricultural Officers and GEOPOTATO staff. Selected farmers managing the demonstration plots produced potatoes for at least five years, were literate, owned a backpack sprayer, and had basic knowledge of fungicides, spraying technique and mobile communication (receiving and reading SMS). In some upazilas, the FP and GEOPOTATO plots were next to each other, but in most upazilas both plots were separated by other plots and up to a few hundred meters apart.

Based on a protocol developed by the GEOPOTATO project, both the farmers managing the GEOPOTATO plot and the FP plot received half a day training and instructions. The aim of the protocol was to align the management of both plots as much as possible except for the late blight control (Section 3.2). A protocol described the recommended amounts of fertilizer, planting density, the use of planting material (cut/whole seed) and a sequence of fungicide types to be applied in GEOPOTATO plots (Table 2.2.2).

The late blight management of the FP plot and GEOPOTATO plot differed in two ways:

1) The timing of fungicide applications: GEOPOTATO farmers sprayed fungicides upon receipt of an SMS / Voice mail, while FP farmers sprayed fungicides according their own experience and needs.

2) The type of fungicides used: GEOPOTATO farmers used a prescribed sequence of fungicides with preventive properties in the beginning of the season and fungicides with more curative properties under high disease pressure later in the season. Some of the fungicides were relatively new to Bangladesh but all are formally allowed to be used to control late blight in potato. FP farmers were completely free to use the fungicide(s) they preferred.

The project gave fertilizers and high-quality seed of the potato variety of farmers' choice, while the demo farmers gave land $\left(15\right.$ decimals $\left.^{1}\right)$, labor and compost/manure at planting. In addition, farmers managing the GEOPOTATO plots received the fungicides for free. Throughout the season, Sub-

\footnotetext{
${ }^{1}$ One decimal is the common unit of area used in Bangladesh and equals about $1 / 100$ acre $\left(=40.46 \mathrm{~m}^{2}\right)$.
} 


\section{Ge冈ه ротато}

Assistant Agricultural Officers were available to support the demo farmers and answer questions about the management.

Both the GEOPOTATO and FP farmers were requested to keep a logbook with management information such as the (amounts and timing of) inputs applied, timing of field operations and specific observations (occurrence of pests and diseases, seed emergence rates, temporary flooding of field, etc.). The logbooks were collected and checked by local Sub-Assistant Agricultural Officers. When the logbook raised questions, the Sub-Assistant Agricultural Officer consulted the farmer and adjusted the logbook information. The logbook was translated into English by GEOPOTATO project staff. The logbook information was used to analyze results of the demo plots and, for example, was helpful to explain anomalies in the performance of plots.

The demonstration sites were marked by signs so that other farmers were informed about the project and the purpose of the demonstrations (Figure 2.1).
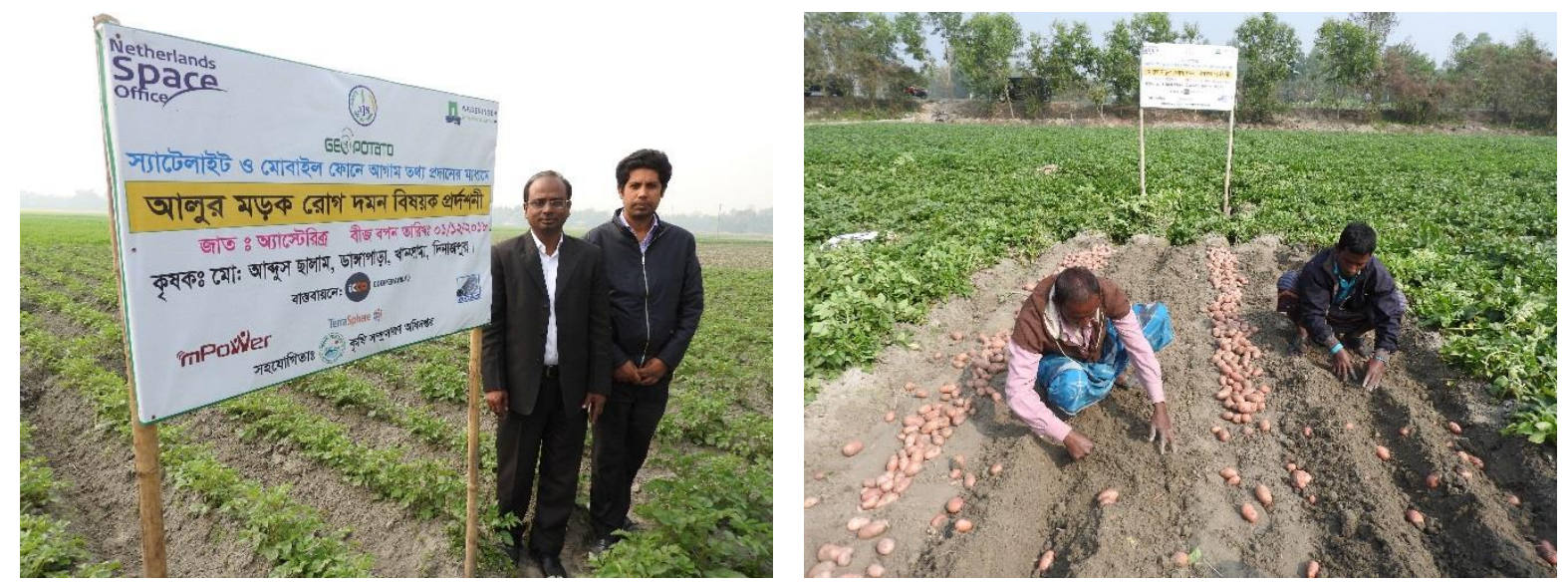

Figure 2.1 GEOPOTATO signs of the demonstration plots.

\subsection{Treatments}

Both the GEOPOTATO plot and FP plot measured 15 decimals $\left(\sim 600 \mathrm{~m}^{2}\right)$. For both plots, the protocol described management recommendations based on good agricultural practices, for example, related to fertilizer management (Table 2.2.1) and plant density ( 60 by $15 \mathrm{~cm}$ ). Demonstration farmers in Rangpur used the potato variety Cardinal, in Dinajpur Asterix and in Munshiganj Diamant were used. 
Table 2.2.1 Recommended fertilizer practices for the GEOPOTATO and farmers' practices demonstration plots.

\begin{tabular}{|c|c|c|c|}
\hline Manure / Fertilizer & $\begin{array}{l}\text { Amount } \\
\text { (kg/15 decimal) }{ }^{1)}\end{array}$ & $\begin{array}{l}\text { Amount } \\
\text { (kg/ha) }\end{array}$ & Instructions for farmers of the demonstration plots \\
\hline Compost / dung & 910 & 15,166 & Mix manure with soil during $1^{\text {st }}$ tillage \\
\hline Urea & 17 & $283^{2)}$ & $\begin{array}{l}\text { Mix half of the amount with the soil before planting; Apply } \\
\text { the rest as topdressing about } 35-40 \text { days after planting. }\end{array}$ \\
\hline Triple Super Phosphate (TSP) & 12 & 200 & Apply the full amount during last / $3^{\text {rd }}$ tillage. \\
\hline Muriate of Potash (MoP) & 15 & 250 & $\begin{array}{l}\text { Mix half of the amount with the soil before planting; Apply } \\
\text { the rest as topdressing about } 35-40 \text { days after planting. }\end{array}$ \\
\hline Gypsum & 6 & 100 & Apply the full amount during last / $3^{\text {rd }}$ tillage. \\
\hline Borax & 1 & 17 & Apply the full amount during last $/ 3^{\text {rd }}$ tillage \\
\hline Magnesium Sulphate $\left(\mathrm{MgSO}_{4}\right)$ & 6 & 100 & Apply the full amount during last / $3^{\text {rd }}$ tillage. \\
\hline
\end{tabular}

1) In this report, one hectare equals 250 decimals.

2) Corresponds with $130 \mathrm{~kg} \mathrm{~N}$ per hectare.

In short, the GEOPOTATO and FP plot only differed in late blight control. In the protocol, a sequence of fungicides and corresponding dose rates were prescribed for the farmers managing the GEOPOTATO plot (Table 2.2.2). The timing of the fungicide application for these farmers was based on the SMS / Voice mail sent by the project. Farmers managing the FP plots were free to use their own management strategy to control late blight, i.e. the type of fungicide, dose, timing and frequency.

Table 2.2.2 Recommended sequence of fungicides used in the GEOPOTATO demonstration plots. The fungicide number shows the order of spraying in the protocol.

\begin{tabular}{llll}
\hline Fungicide & $\begin{array}{l}\text { Amount of spray water } \\
\text { (l/decimal) }\end{array}$ & $\begin{array}{l}\text { Fungicide quantity } \\
\text { (g or ml/ 15 decimals) }\end{array}$ & $\begin{array}{l}\text { Fungicide quantity } \\
\text { (kg or I /ha) }\end{array}$ \\
\hline 1. Revus 250 SC & 2 & 36 & 0.6 \\
2. Revus 250 SC & 2 & 36 & 0.6 \\
3. Antracol 70 WP & 2 & 150 & 2.5 \\
4. Dithane M-45 & 2 & 134 & 2.2 \\
5. Dithane M-45 & 2 & 134 & 2.2 \\
6. Melody Duo 66.8 WP & 2 & 120 & 2 \\
7. Melody Duo 66.8 WP & 2 & 120 & 2 \\
8.Secure 600 WG & 2 & 90 & 1.5 \\
9. Secure 600 WG 1) & 2 & 90 & 1.5 \\
\hline
\end{tabular}

1) repeated if needed, i.e. depending on the number of SMS / Voice mail sent.

\subsection{Observations and methods of analyses}

At the end of the growing season, $12 \mathrm{~m}^{2}$ of the plots were harvested, the percentage of the foliage infected by late blight was estimated and the external quality of the potato tubers assessed.

Several aspects of the demonstration plots have been analysed and are reported here:

1. The management: Was the management of the GEOPOTATO demo's according the protocol?

2. Yields of GEOPOTATO and FP plots: What was the yield of the GEOPOTATO plots compared to the FP plots? Can yield differences between both plots be attributed to differences in late blight control? We analysed the relationship between the length of the growing period and yield to determine anomalies as one may expect that yields increase with longer growing periods when the production is not reduced by grow-limiting factors such as diseases and plagues. This relationship gives an indication whether growth and production followed a normal pattern. The 
length of the growing period is defined as the number of days between the time of planting and harvesting.

3. Cost-benefit of late blight control in the GEOPOTATO plots compared to FP plots: We calculated the costs of the fungicides used in the GEOPOTATO plots and in the FP plots. Subsequently, we estimate the financial benefit for farmers of the GEOPOTATO plot compared to FP. We estimate the financial benefit for farmers by valuing the extra yield gain in the GEOPOTATO plots over FP plots subtracted by the extra costs for the fungicide package used in the GEOPOTATO plots. We did not value the costs of labour associated with spraying (e.g. preparing sprayer, spraying, cleaning sprayer) as labour opportunity costs are assumed zero. 


\section{Results}

\subsection{Management of demonstration plots}

Table 3.3.1 shows the major management characteristics of the control plots and GEOPOTATO plots in Rangpur, Dinajpur and Munshiganj. Planting of the potatoes was almost on the same day in the three districts, despite that Munshiganj is in the Centre and Rangpur and Dinajpur in the North of Bangladesh. The moment of harvesting was also almost the same in Rangpur and Dinajpur, but in Munshiganj it was on average 17 days later, resulting in 17 days longer growing period on average. Although the FP and GEOPOTATO plots were managed by different farmers the average moment of planting and harvesting were (almost) the same in the three districts. Hence, any yield differences in a district between the control and GEOPOTATO plots cannot be attributed to differences in the field period of the crops. The yield-relationships of the plots in Rangpur and Dinajpur are analysed together in section 3.4 as agro-ecological conditions and growing period were the similar.

Nitrogen fertilizer use was higher than recommended in the control plots, especially in Dinajpur. In Munshiganj, the average $\mathrm{N}$ gift of the control plots is an underestimation as one of the farmers applied more $\mathrm{N}$ fertilizers than recommended but we do not know how much more was applied. In general, nitrogen availability stimulates vegetative growth of the crop and delays tuber initiation. In combination with a short growing season, high nitrogen availability may reduce potato yields. However, the differences in nitrogen applied are small between FP and GEOPOTATO in most plots, only in Dinajpur FP plots received on average about 25\% more nitrogen.

Table 3.3.1 Major characteristics of the GEOPOTATO and Farmers' practice (FP) demonstration plots in Rangpur, Dinajpur and Munshiganj.

\begin{tabular}{|c|c|c|c|c|c|}
\hline $\begin{array}{l}\text { District (n) } \\
\text { GEOPOTATO / FP plot }\end{array}$ & Average planting date & $\begin{array}{l}\text { Average harvesting } \\
\text { date }\end{array}$ & $\begin{array}{l}\text { Growth duration } \\
\text { (days) }\end{array}$ & $\begin{array}{l}\mathrm{N} \text { applied (kg } \\
\mathrm{N} / \mathrm{ha} \text { ) }\end{array}$ & $\begin{array}{l}\text { \# fungicide } \\
\text { sprays }\end{array}$ \\
\hline \multicolumn{6}{|l|}{ Rangpur (7): } \\
\hline GEOPOTATO & 25 November 2018 & 20 February 2019 & 88 & 131 & 7.4 \\
\hline FP & 25 November 2018 & 21 February 2019 & 88 & 153 & 6.0 \\
\hline \multicolumn{6}{|l|}{ Dinajpur (6): } \\
\hline GEOPOTATO & 26 November 2018 & 22 February 2019 & 88 & 130 & 7.3 \\
\hline $\mathrm{FP}$ & 28 November 2018 & 22 February 2019 & 86 & 165 & 6.0 \\
\hline \multicolumn{6}{|l|}{ Munshiganj (6): } \\
\hline GEOPOTATO & 23 November 2018 & 8 March 2019 & 105 & 130 & 8.8 \\
\hline FP & 24 November 2018 & 8 March 2019 & 105 & 137 & 4.5 \\
\hline
\end{tabular}

\subsection{Late blight control}

Annex I shows the moment of spraying and the fungicides used in the GEOPOTATO and FP demonstration plots in Rangpur, Dinajpur and Munshiganj during the 2018-2019 season. In general, the GEOPOTATO farmers adhered to the prescribed sequence of fungicides. However, in the beginning of the growing season, some GEOPOTATO farmers applied two fungicides at the same moment as they (their mobile telephone number) appeared twice in the GEOPOTATO client database that was used to dispatch the SMS / Voice mail. This issue was solved quickly after demo farmers started to ask what to do with the information. In addition, GEOPOTATO farmers did not get an SMS / Voice mail to use Antracol and, therefore, Antracol was not applied according the protocol. 
FP farmers in Rangpur and Dinajpur sprayed their potato crop on average six times and GEOPOTATO farmers seven times (see also Table 3.3.1). In Munshiganj, this difference is larger, five times for FP plots vs nine times for GEOPOTATO plots.

\subsection{Late blight infection}

Four of the 13 FP plots in Rangpur and Dinajpur showed late blight infections at harvest. The highest infection rate was estimated as $13 \%$ of the canopy. Only one of the GEOPOTATO plots in Rangpur and Dinajpur showed minor late blight symptoms at harvest, i.e. less than $1 \%$ of the canopy was infected.

Three of the six FP plots in Munshiganj showed minor late blight symptoms, i.e. less than $4 \%$ of the leave area was infected at harvest, and only one on the six GEOPOTATO plots showed minor late blight symptoms.

According farmers and extension staff, late blight pressure was mild in the three districts in the season 2018-2019, much less than in the 2017-2018 season.

\subsection{Yield relationships}

Table 3.3.2 shows the average potato yields achieved in the GEOPOTATO plots and FP plots in the three districts Rangpur, Dinajpur and Munshiganj. The yield of one of the GEOPOTATO plots in Munshiganj was discarded in the analysis as the seed tubers were attacked/eaten by rats and germination was only $20 \%$. Average potato yields of the GEOPOTATO plots were higher than the FP plots for all three districts. In Dinajpur, the average GEOPOTATO plot yield was $19 \%$ higher, in Munshiganj $2 \%$, and Rangpur took an intermediate position with $13 \%$ higher yields in favour of the GEOPOTATO plots. The overall weighted yield difference between GEOPOTATO and FP demo plots in the three districts was $9 \%$.

Table 3.3.2 Yields of GEOPOTATO and Farmers practice (FP) demonstration plots in Rangpur, Dinajpur and Munshiganj, and the relative yield difference of the GEOPOTATO plot compared to the FP plot.

\begin{tabular}{lll}
\hline District & Yield (t/ha) & Relative yield difference (\%) \\
GEOPOTATO / FP plot ( $\mathbf{n})$ & & 13 \\
\hline Rangpur: & 41.2 & \\
$\quad$ GEOPOTATO (7) & 36.5 & 19 \\
FP (7) & & \\
Dinajpur: & 39.5 & \\
$\quad$ GEOPOTATO (6) & 33.2 & 2 \\
$\quad$ FP (6) & 41.8 & \\
Munshiganj: & 41.1 & 9 \\
$\quad$ GEOPOTATO (5) & & \\
FP (6) & 40.8 & \\
Weighted average & 36.9 & \\
$\quad$ GEOPOTATO (18) & \\
$\quad$ FP (19) &
\end{tabular}

Figure 3.1 shows the relationships between the length of the growing period and potato yields in Dinajpur and Rangpur using the same data set but in different configurations. The yield of one the FP plots was discarded as it was severely affected by late blight. Figure 3.1ab shows the pooled data of GEOPOTATO plots and FP plots in Dinajpur and Rangpur, respectively. The difference between the minimum and maximum growing period of plots was small with 11 days in Dinajpur and 9 days in 
Rangpur. Yet, for both districts a positive relationship could be established between the length of the growing period and yield: As one may expect, yields increased with a longer growing period. In Dinajpur, this relationship is more robust with an $\mathrm{R}^{2}$ of $52 \%$. The corresponding equation shows that in the range of given growing periods yields increased with about 1,250 kg per hectare per day. In Rangpur, this relationship is less robust $\left(R^{2}=13 \%\right)$ and yields increased with about $470 \mathrm{~kg}$ per hectare per day during the analyzed growing period.

Figure 3.1c shows the pooled data of GEOPOTATO and FP plots in both Dinajpur and Rangpur. The $\mathrm{R}^{2}$ is $37 \%$ and yields on average increased with about $1,000 \mathrm{~kg}$ per hectare per day during the analyzed period. Figure 3.1d shows the same data separately for GEOPOTATO and farmers' practice plots. Discarding the results of one FP plot for reasons described before, the relationship for FP plots is most robust $\left(R^{2}=58 \%\right)$. The $R^{2}$ of the GEOPOTATO plots is much lower (22\%). Because of the data scatter of the GEOPOTATO plots it is difficult to draw firm conclusions, but there seems a tendency that the GEOPOTATO late blight control was especially beneficial for crops with a short growing period. This is in contrast with the common understanding that a proper late blight control extends the lifespan of the crop canopy and, therefore, its yield effect especially shows in crops with a longer growing period. However, a combination of overall short growing periods, few scattered data points, and low late blight pressure (Section 3.3) could be the reason that this effect did not show up in the 2018-2019 season.

(a) Dinajpur

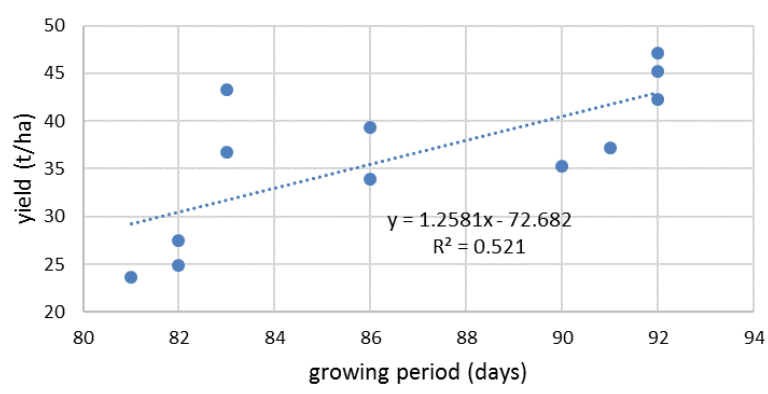

(c) Dinajpur and Rangpur

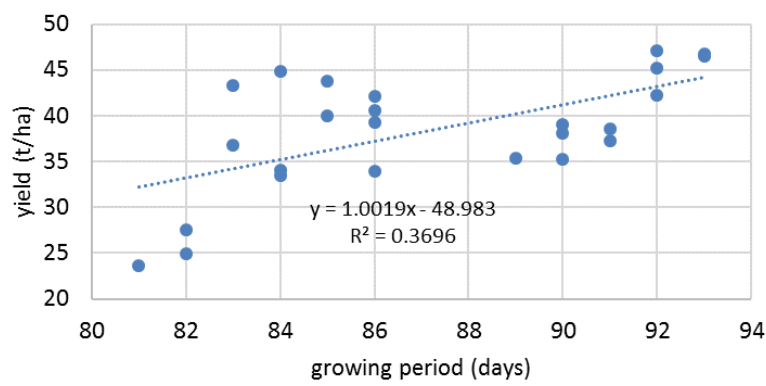

(b) Rangpur

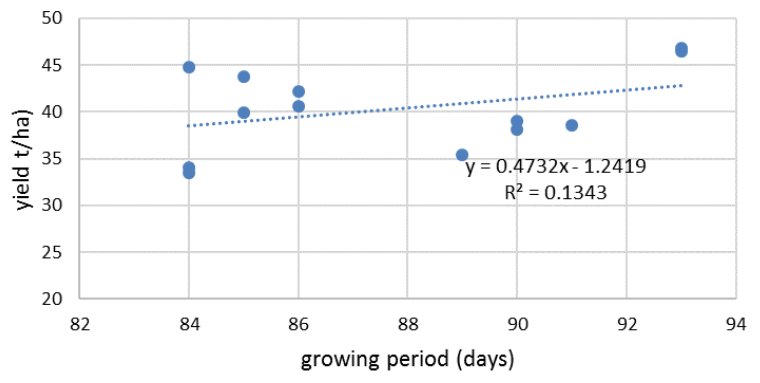

(d) Dinajpur \& Rangpur

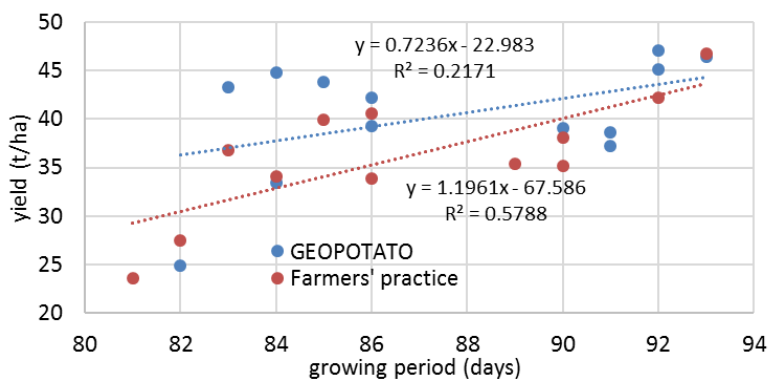

Figure 3.1 Relationship between the growing period and potato yield for (a) pooled GEOPOTATO and farmers' practice plots in Dinajpur, (b) pooled GEOPOTATO and farmers' practice plots in Rangpur, (c) pooled data of GEOPOTATO and farmers' practice plots in Dinajpur and Rangpur, and (d) pooled GEOPOTATO and farmers' practice plot data in Rangpur and Dinajpur.

Figure 3.2 shows the relationships between the growing period and potato yields in Munshiganj for GEOPOTATO plots and FP plots. The FP plots do not show a clear relationship because of the data scatter. The GEOPOTATO plots show a better relationship $\left(R^{2}\right)$ but it is based on five data points only. 
Daily production increase based on this relationship was about $300 \mathrm{~kg} /$ day during the observed growing periods.

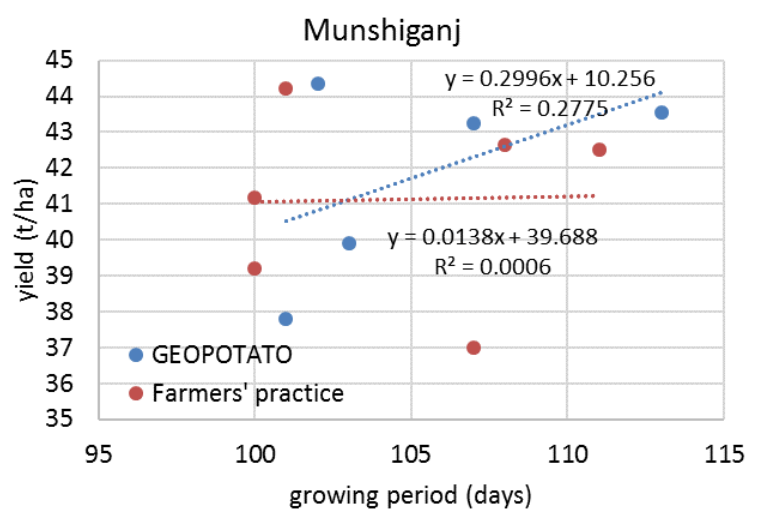

Figure 3.2 Relationship between the growing period and potato yields for GEOPOTATO and farmers' practice plots in Munshiganj.

\subsection{Cost-benefit analysis}

Table 3.3.3 shows the average costs of the fungicides used in the GEOPOTATO plots, not differentiated according district. Because GEOPOTATO farmers across the three districts did not apply the fungicides exactly according to the protocol (Section 3.2) the average actual costs of GEOPOTATO demo plots have been calculated per district.

Table 3.3.3 Costs of the fungicides used in the GEOPOTATO demo plots.

\begin{tabular}{lllllll}
\hline Fungicide type & $\begin{array}{l}\text { amount applied } \\
\text { (per 15 decimal) }\end{array}$ & $\begin{array}{l}\text { unit price (BDT per } \\
\mathbf{1 0 0} \mathbf{~ m l ~ o r ~ 1 0 0 ~ g ) ~}\end{array}$ & $\begin{array}{l}\text { costs (BDT/15 costs (BDT/ha) } \\
\text { decimal) }\end{array}$ & $\begin{array}{l}\text { costs } \\
\mathbf{2} \text { (Euro/ha) }\end{array}$ \\
\hline Revus & 36 & $\mathrm{ml}$ & 365 & 131 & 2190 & 23 \\
Dithane M45 & 134 & $\mathrm{~g}$ & 90 & 121 & 2010 & 3600 \\
Melody Duo 66.8 WP & 120 & $\mathrm{~g}$ & 180 & 216 & 180 & 3000
\end{tabular}

The FP farmers sprayed less than the GEOPOTATO farmers during the 2018/19 season but only used Mancozeb containing fungicides (Annex I). In the cost calculation of FP plots, we assume that Dithane M45 has been used in FP.

To calculate the financial benefit, we assumed a potato price of $870 \mathrm{BDT} / 100 \mathrm{~kg}$ in Munshiganj, and 740 BDT/100 kg in Rangpur and Dinajpur based on prices in Munshiganj and Rangpur during the 2017/18 season (Pronk et al., 2019).

Based on these assumptions, the price of fungicides shown in Table 3.3.3, and the yield data shown in Table 3.3.2 the cost-benefit of the GEOPOTATO demo plots and FP plots are shown in Table 3.4.

\footnotetext{
21 Euro $=94$ BDT
} 
Table 3.4 Cost-Benefit calculations of GEOPOTATO demo plots compared to farmer practice (FP) demo fields in Rangpur, Dinajpur and Munshiganj in the 2018/19 season.

\begin{tabular}{|c|c|c|c|c|c|c|}
\hline & \multicolumn{2}{|c|}{ Fungicide costs } & \multirow{3}{*}{$\begin{array}{c}\text { Difference in } \\
\text { fungicide costs } \\
\text { GEOPOTATO - FP } \\
\text { Euro/ha }\end{array}$} & \multirow{2}{*}{\multicolumn{2}{|c|}{$\begin{array}{l}\text { Yield difference } \\
\text { GEOPOTATO - FP } \\
\end{array}$}} & \multirow{3}{*}{$\begin{array}{c}\text { net benefit } \\
\text { GEOPOTATO -FP } \\
\text { Euro/ha }\end{array}$} \\
\hline & \multirow{2}{*}{$\frac{\text { GEOPOTATO }}{\text { Euro/ha }}$} & \multirow{2}{*}{$\frac{\text { FP }}{\text { Euro/ha }}$} & & & & \\
\hline & & & & $\mathrm{Kg} / \mathrm{ha}$ & Euro/ha & \\
\hline Rangpur & 262 & 126 & 136 & 4,700 & 370 & 234 \\
\hline Dinajpur & 248 & 126 & 122 & 6,300 & 496 & 374 \\
\hline Munshiganj & 314 & 95 & 220 & 700 & 65 & -155 \\
\hline $\begin{array}{l}\text { Weighted } \\
\text { average }\end{array}$ & & & & & & 173 \\
\hline
\end{tabular}

The average costs for fungicides used in the GEOPOTATO plots varied between 314 Euro/ha in Munshiganj and 248 Euro/ha in Dinajpur associated with the number of sprays in both districts. Fungicide costs in the FP demo's in all three districts were considerably lower associated with the use of less costly fungicide products and less sprays (Table 3.3.1). As a result, GEOPOTATO demo treatment were between 122 Euro/ha (Dinajpur) and 220 Euro/ha (Munshiganj) more expensive than the FP demo fields.

Yields of GEOPOTATO demo plots were higher than the FP plots in all districts ranging from $700 \mathrm{~kg} / \mathrm{ha}$ in Munshiganj up to 6,300 kg/ha in Dinajpur. The higher yields in the GEOPOTATO demo plots correspond with additional gross financial returns varying between 65 Euro /ha (6,090 BDT/ha) in Munshiganj and almost 500 Euro/ha (35,152 BDT/ha) in Dinajpur.

The net benefit of the GEOPOTATO demo plots, i.e. additional financial return minus the additional fungicide costs, varies between 374 Euro/ha in Dinajpur (35,152 BDT/ha) and an economic loss of 155 Euro/ha (14,543 BDT/ha) in Munshiganj. The net benefit of GEOPOTATO demo farmers in Rangpur was 234 Euro/ha (21,996 BDT/ha). The negative net returns in Munshiganj imply that the gross financial returns due to higher yields did not outweigh the higher costs associated with the fungicide applications in the GEOPOTATO demo plots. Three out of the five GEOPOTATO demo farmers in Munshiganj sprayed 10 times or more in the 2018/19 season while yield benefit of the GEOPOTATO plot was insignificant compared to Dinajpur and Rangpur. In contrast, in Rangpur and Dinajpur the GEOPOTATO demo plots show great financial net benefits. Overall, the weighted average net benefit of the GEOPOTATO treatment in the three districts in the 2018/19 season was 173 Euro/ha. 


\section{Discussions and conclusions}

In general, farmers in charge of the GEOPOTATO demo plots sprayed according the defined sequence of fungicides that was communicated in the SMS / Voice mail alerts. Only in the beginning of the season problems in dispatching messages caused that some farmers applied two fungicides at the same time. Farmers in charge of the FP plots sprayed less than the farmers controlling late blight in the GEOPOTATO plots. Especially in Munshiganj, GEOPOTATO demo farmers sprayed more frequently than FP farmers.

On average, yields of the GEOPOTATO and FP demo plots were high, between 33 and $42 \mathrm{t} / \mathrm{ha}$, while the national average potato yield in Bangladesh is about $20 \mathrm{t} / \mathrm{ha}$. This difference may be caused by the good agricultural practices applied in both the GEOPOTATO and FP plots, but also because of the small harvested area $\left(12 \mathrm{~m}^{2}\right)$, which commonly results in an over-estimation of the yield on hectare basis (Casley and Kumar, 1988). In general, potato growth and production showed a normal pattern and increased with a longer growing period.

At harvest, more FP demo plots had late blight symptoms than the GEOPOTATO demo plots, but only low levels of infection were reported. On average, GEOPOTATO demo plots had $9 \%$ higher yields than the FP demo plots. In Dinajpur the difference between GEOPOTATO and FP plots was even $19 \%$ but in Munshiganj it was only $2 \%$. It is uncertain to what extent the higher $\mathrm{N}$ application of the FP pots in Dinajpur has affected the yields negatively.

The higher gross returns associated with the higher potato yields in Rangpur and Dinajpur outweighed the higher costs of the fungicides used in the GEOPOTATO demo plots. The GEOPOTATO demo plots resulted on average in the three districts in a financial benefit of 173 Euro/ha. 


\section{References}

Casley, D.J., and Kumar, K., 1988. The collection, analysis and use of monitoring and evaluation data. Baltimore, MD: John Hopkins University Press for the World Bank.

Pronk, A.A., N. Islam, H. Ahsan, M.M. Rahman, G.J.T. Kessel and H. Hengsdijk, 2017a. Baseline study GEOPOTATO. GEOPOATO Report 2. Dhaka / Wageningen.

Pronk, A.A., G. Kessel, H. Ahsan, M.M. Rahman, S.A. Hill, N., Islam, J.M. Michielsen, H. Hengsdijk, 2017b. Baseline study Rangpur GEOPOTATO. GEOPOATO Report 4. Dhaka / Wageningen.

Pronk, A.A., H. Ahsan, M.M. Rahman, G. Kessel and H. Hengsdijk, 2017c. Geo data for late blight control in potato: evaluation of decision support service in Bangladesh, 2016-2017. GEOPOATO Report 3. Dhaka / Wageningen.

Pronk, A.A., Hengsdijk, H., Hasib Ahsan, Michielsen, J.M., 2019. Geo data for late blight control in potato Evaluation of decision support service in Bangladesh, 2017-2018. GEOPOATO Report 5. Dhaka / Wageningen.

FRG, 2012. Fertilizer Recommendation Guide. Bangladesh Agricultural Research Council (BARC), Farmgate, Dhaka 1215. 274 p.

Rabbani M.G., M.A. Siddique, M.M. Islam and M.S. Islam, 2010. The potato sector in Bangladesh: its challenges and opportunities. Katalyst, Dhaka, Bangladesh. $144 \mathrm{p}$. 


\section{бєอจротато}

\section{ANNEX I Spray schedule}

Actual spray schedule in GEOPOTATO and FP demo plots in Rangpur, Dinajpur and Munshiganj during 2018/19 season. RE = Revus; Ma = Mancozeb; Me = Melody Duo; Se = Secure; Th = Thiovit; An = Antracol

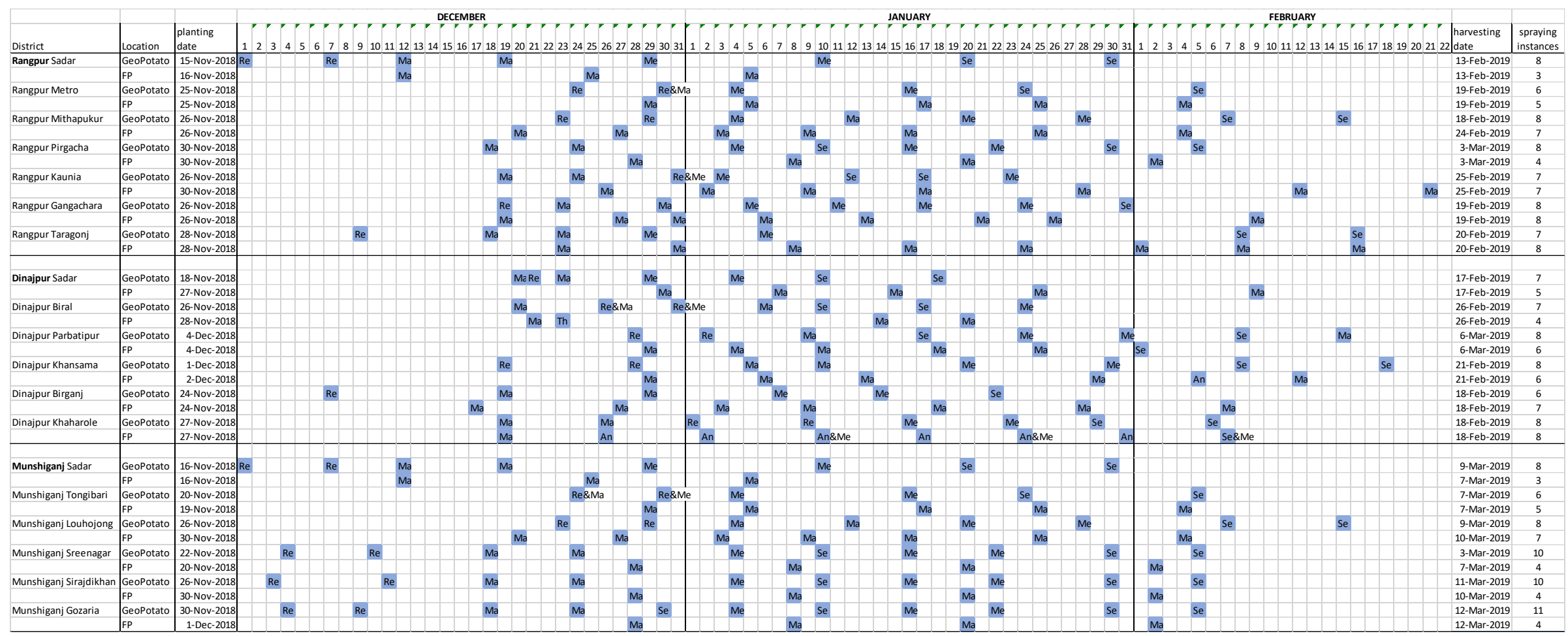


GE匃 ротато 